\title{
POSSIBILITIES OF TEACHERS FOR MONITORING, DETECTING AND RECORDING OF INDIVIDUAL CHARAC- TERISTICS OF STUDENTS IN EARLY SCHOOL AGE
}

\author{
Dr. Tatjana Koteva-Mojsovska, "Ss Cyril and Methodius" University \\ Faculty of Pedagogy "St Kliment Ohridski”, Skopje, Republic of Macedonia \\ E-mail: tanja.koteva@yahoo.com
}

Received: May, 17.2015.

Accepted: June, 04.2015.

Original Article

UDK 159.922.72-053.5

\begin{abstract}
The monitoring and recording of the individual characteristics of children are very important for the development of quality education. Also the views of the teachers about the differences in the development, the potentials and the affinities of the children in the early school period are especially important. The quality education process in the modern school should be adapted to the individual potentials of the children. The children are individuals with their own integrity and characteristics. (Johnston and Halocha, 2010). They have individual pace and develop individual approaches in the learning process. This individual pace in the development of the children requires the teachers to regularly monitor and record the individual characteristics and differences of the children, monitoring the children's interests, planning instruction which will adapt to the different learning approaches and the different pace of progress of the students.

Setting out from this paradigm, this paper, which is based on a realized research, aims to offer findings about the treatment of the individual characteristics of the early school-age children in our country. According to this, we carried out a research in four primary schools in Skopje, which showed us that the teachers lack the appropriate conditions and possibilities to monitor and record the individual characteristics and the specific differences of the students in the early school period.

Keywords: Modern school, Individual characteristics, Early school age, Monitoring and recording.
\end{abstract}

Corresponding Author

Dr. Tatjana Koteva-Mojsovska, "Ss Cyril and Methodius" University, Faculty of Pedagogy "St Kliment Ohridski", Skopje, Republic of Macedonia E-mail: tanja.koteva@yahoo.com

\section{INTRODUCTION}

Trying to create a modern school we got stuck on the way which leads to creating the main precondition for a modern school - support of the individual characteristics of the students. The realization of this process has proven to be very difficult in the educational practice, especially regarding the first three grades of primary education, where it is in fact most needed. Namely, the treatment of the individual characteristics in the practice moves in two directions: 1 . creating a flexible education process by every teacher according to the individual potentials of the child/student, and 2. creating an educational context which is equal for every student in the same grade. The first is mainly a reflection of an enthusiastic practice, while the second is a reflection of the real (traditional) practice. About the second direction we can say" the children in the school are not "independent researchers", and there is great probability that many of them will lose their competencies and potentials, which were developed through their autonomy in kindergarten." (Koteva-Mojsovska, 2014). This means that we have forgotten the idea that a child is an individual with personal characteristics, needs and potentials, whose development depends on many factors.

The pedagogical discourse is clear: a child has to learn depending on his or her personal pace and with an individual approach in this process. This means that each student has a different cognitive, social and emotional potential. Especially this is underlined by the new ecological approach of Bronfenbrenner, according to which everyone needs various interactive processes for understanding the environment (Bronfenbrener, J. 1997). The teach- 
ers have an obligation to provide the necessary conditions which allow the children to learn strategies and methods for good quality independent learning. The individual pace of development and progress require of the teacher to additionally engage in terms of the monitoring and recording of the individual differences, monitoring of the children's interests, planning instruction adapted to the different learning approaches and the different progress pace of the students. In this case, teachers should promote the game as a most suitable method for monitoring the child development, and for using various kinds of learning for each pupil (Samuelsson, I. P., and Carlsson, M. A. 2008). This requires freedom and creativity, as well as an entire array of different components of pedagogical theories and practices.

At first, in order to achieve this level of individual treatment in the school the teacher should continue keeping the child's portfolio, which is started as early as pre-school institution (Peters, S. et al., 2009, Einarsdóttir $\mathrm{J}, 2002)$. It is one of the basis for building a school that is based on the specifics of children.

Today we say with ease "A school according to the needs of the child". However, we are not quite convinced about the "according" part of this statement. Is it really so? Is the pedagogical theory ahead of the practice when it speaks of crystal or indigo children? Does the theory of differences lead towards the theoretical interpretations without taking into consideration the systemic requirements for its practical implementation? Namely, the pedagogical practice emphasizes that one of the important preconditions for respecting the differences is providing possibilities for the teachers to monitor and record the individual characteristics of the early school-age children, via a high level of systemic setting and organization. In this context, we will present the following specific conditions:

- Establishing standards for learning and development of the children/students on a national level,

- Establishing standards about the number of children in a given grade and their age,

- Establishing criteria and instruments for monitoring and recording,

- Creating a guidebook (a guide) for monitoring and recording the individual characteristics,

- Systemic keeping of a portfolio for every child and keeping an integral document for comparative recording of the differences among the children in the same grade,
- Permanent refreshing of the knowledge of the teachers regarding the developing characteristics of the children regarding a certain developing period,

- Cooperation among the family, the teacher and the school, and

- Providing a team approach in the process of interpreting and using the results from the monitoring of the individual characteristics.

Unfortunately, the individual experiences of some of the teachers in our country show that there are not adequate conditions which would allow monitoring and support of the individual characteristics of early schoolage students. This is the reason why we focused on researching the possibilities which the teachers have to monitor and record the individual characteristics of children/students in early school-age.

\section{METHODOLOGICAL FRAMEWORK}

The role of understanding the individual characteristics of the students, especially in the early school age, as a basis for the development of strategies for supporting an interactive and modern teaching process, imposed the need to detect the actual possibilities in the practice for monitoring and recording the individual characteristics of children from the first three grades of primary education in Skopje. Regarding this matter, we were interested about the following question: To which extent, within one period, is the teacher able to monitor, support and record the individual achievements, interests and potentials of children, according to conditions provided for this purpose?

To determine the possibilities which the teachers have for monitoring, recording and support of the individual characteristics, we took the following conditions into consideration:

- Standards for learning and development,

- The guidebook (guide) and the instruments for monitoring and recording individual characteristics,

- The children's portfolios and the guidebook for keeping a portfolio,

- The number of children in a grade and the age difference among them,

- The knowledge of the teachers of the specifics of children in the grade they are in 
charge of,

- The comparative approach in recording the characteristics of children in a same grade,

- The teacher's knowledge of the family climate of the child.

For this purpose we used the techniques survey and interview with teachers from the first three grades in four primary schools in Skopje. These techniques helped us to determine the attitudes and opinions of the teachers regarding the question of our interest, i.e. whether they have the possibility to monitor and record the individual characteristics of the children/students and whether they come across obstacles regarding this matter. The emphasis was also placed on determining the opinions of the teachers regarding the importance of monitoring and recording the individual characteristics of the children.

\section{DATA ANALYSIS}

The data analysis resulted with alarming findings related to the need of intervention regarding the treatment of the individual potentials of the early school-age students. For example, we came across interesting the answers to the following question: Are there conditions for continuous monitoring and recording of the individual characteristics of every student separately? Namely, $50 \%$ of the teachers believe that there are partial conditions for continuous monitoring and recording of the individual characteristics of every student separately, $20 \%$ of the teachers answered that there are no conditions at all, while only $28 \%$ answered that there are conditions for this type of work. The results are alarming if we take into consideration that the answer "partial" does not in fact meet the needs for a seamless realization of the individual monitoring. The partial existence of conditions means that the teachers are faced with the choice to independently provide these conditions and complete them or finish the work partially, which would potentially lead to abandoning the practice in question.

Most of the respondents contribute the reasons for the lack of conditions for monitoring and recording of the individual characteristics of the children to the following:

- The age of children $(94.4 \%)$,

- The number of children in a grade $(66.7 \%)$

- The great age difference among children (youngest to oldest child) in the same grade $(83.3 \%)$,

- Lack of standards for learning and development $(66.7 \%)$.

Regarding the question if you have the possibility to monitor and record the individual characteristics of every student separately in a continuous and organized manner, please state the way in which you do it, we received the following results: $50 \%$ of the teachers answered that they monitor the individual characteristics of children freely and according to their personal convictions, $33 \%$ of the teachers answered that they do this with the help of a monitoring instrument which they personally prepare, and $17 \%$ answered that they use a monitoring instrument prepared on a national level. If such an instrument does exist, it is alarming why all teachers, covered by this research, do not use it. This information directs to the probability that the instrument which is used by $17 \%$ of the teachers is not adequate for monitoring or is unavailable to all teachers. We are also left to assume that if it does exist, not all teachers are informed of its existence. In all these cases, the fact remains that most of the interviewed teachers do not use a purpose-developed instrument for monitoring and recording the individual characteristics of the students, which allows for subjective monitoring criteria.

Regarding the guidebook for monitoring and recording the individual characteristics of children, $65 \%$ of the teachers think that there is an incomplete guidebook; $23 \%$ of the teachers answered that a guidebook does not exist; while $12 \%$ answered that they monitor and record the individual characteristics with the help of a guidebook. If we attempt to interpret these answers, we will probably make the same conclusion as we have with the previous question. However, there is a difference regarding this case, which resulted from the interpretation of the answers, according to which the guidebook is created on a school level. Nevertheless, the percentage of answers according to which there is a complete or an incomplete guidebook, is sufficient for us to conclude that it is not an official and obligatory document, which again is alarming.

Regarding the keeping of a student's portfolio, where the teacher records the progress of students, we received specific data (Table 1) which show that the teacher monitors the child and makes an assessment about the progress of the child only when there are specific activities $(100 \%)$. These activities however, do not refer to the developing specifics. Namely, in this case, the assessment is general 
and mostly based on the recollections of the teacher up until the moment of recording the progress. The answers are presented in Table 1 where the teachers were allowed to choose several answers.

Table 1. The information is entered into the student's portfolio

\begin{tabular}{lc}
\hline $\begin{array}{l}\text { During every period } \\
\text { according to the } \\
\text { specific subject } \%\end{array}$ & $\begin{array}{c}75,5 \% \text { refers to } \\
\text { children with special } \\
\text { needs }\end{array}$ \\
\hline $\begin{array}{l}\text { According to the } \\
\text { specific activities of } \\
\text { the students\% }\end{array}$ & $100 \%$ \\
\hline Once a month \% & $3,12 \%$ \\
\hline $\begin{array}{l}\text { Once in three } \\
\text { months \% }\end{array}$ & $/$ \\
\hline Rarely \% & $/$ \\
\hline
\end{tabular}

Note: The table shows that the regular monitoring and recording during every period regarding a specific subject is carried out only for "separate students" (75.5\%), which is understandable given the fact that the deviations in the development of these students are subject to close observation.

According to the interview carried out with the teachers, we came to the conclusion that the monitoring and the assessment of the achievements of the students are strained as a result of the great number of children in a grade. The number of children was stated as the primary reason by $90.62 \%$ of the teachers.

We find even more alarming the data (Table 2), also confirmed by the interview, that the recording of data related to the individual characteristics of the children, as the basis for instruction "according" to the needs of the child (the subject of our interest) is carried out only on rare occasions. Regarding this questions, the respondents answered that they do not keep a special document for summative and comparative recording of the differences they notice regarding all children in the grade they are in charge of. The respondents offered several reasons for this: $96.87 \%$ of the interviewed teachers do not record the differences among the children because they feel that they are not obligated to do this, $71.87 \%$ stated the lack of a guidebook as a reason which hinders these activities, while the lack of time was stated as a reason by $59.37 \%$ of the interviewed teachers.
Table 2. Interviewed teachers comment about recording the individual differences in a separate summative document

\begin{tabular}{lcc}
\hline Interview answers & $\mathrm{N}$ & $\%$ \\
\hline It is not obligatory & 32 & 96,87 \\
\hline $\begin{array}{l}\text { There is not a guidebook for } \\
\text { this }\end{array}$ & 32 & 71,87 \\
\hline Lack of time & 32 & 59,37 \\
\hline $\begin{array}{l}\text { The age difference among the } \\
\text { students }\end{array}$ & 32 & $/$ \\
\hline
\end{tabular}

It is interesting to mention that regarding the answers to this question, the age difference among the students was not mentioned as a reason for not monitoring and recording the individual differences and characteristics among the children in the first three grades of primary school. On the other hand, science supports the need of a comparative approach in recording the differences, especially if there is a notable age difference among the students.

During the interview the teachers answered that they monitor the progress of the individual development of the children, however, according to them, this does not include the differences among the children, which could be the basis for development and realization of various learning strategies and approaches. In fact, regarding the differences, the teachers confirmed their attitudes, which we also recorded in the survey, as reasons for the inability to monitor and record the individual characteristics of the children during a single period:

1. They are not obligated to carry out this type of activities,

2. They lack the time to do this, and purpose.

3. They do not have a guidebook for this

Along with these reasons, the teachers avoid an official form of monitoring and recording the individual differences of the children. On the other hand, all teachers agreed that apart from knowing the children, their characteristics and differences, they are not always able to adapt instruction accordingly. This implies to the informal use of one of the basic elements for development of quality instruction.

In order to better learn the individual differences of the students, it is especially important to learn about the overall family climate (Johnston and Halocha, 2010). This activity is part of the cooperation with the parents which can also be done by visiting the homes of the students. This is especially important in the first three grades of primary school when the teacher is still in the process 
of getting to know the children in the grade (Koteva - Mojsovska, T., 2006). However, the results unfortunately show that this form of communication with the parents is $100 \%$ realized exclusively in specific situations (the child's adaptation problems, behavior problems or lack of interest in learning and school).

Regarding the possibilities of the teachers to support and monitor the individual characteristics of the students as well as how well informed they are, we were interested to see the different types of individual characteristics and differences among the early school-age children. We tried to find out their attitudes regarding this question with a survey - scale. The teachers were asked to choose several options related to the greatest differences among the first grade students in primary school. Most of the respondents, i.e. $66.7 \%$ contribute this difference to the concentration levels of the students and $66.1 \%$ contribute it to the pace and relevance of learning in relation to the amount of learning material. The remaining answers refer to the learning of specific instructional material $(55.5 \%)$, adaptation to school, independent learning, etc. According to teachers, the differences in adaptation, as well as concentration are probably due to the fact that not all children enroll in kindergartens prior to enrolling in primary school. Also, some of them go to kindergarten from the youngest age, three or four years of age, some before starting to school, in preschool age, etc. However, although teachers have knowledge about differences in individual characteristics in children, the results of the overall survey show that this knowledge is not based on facts and is not result of an organized observation on children.

Regarding the status of the individual differences of the students, it is also intriguing that $83.3 \%$ of the teachers think that there is a great age difference between the youngest and the oldest child in the grade, which hinders the monitoring and recording activity, and especially the support of their individual development.

\section{CONCLUSION AND SUGGESTION}

The analysis of the data gathered by the research allows us to conclude that the teachers do not have the required possibilities to monitor record and support the individual characteristics of the early school-age stu- dents. This is especially due to the lack of a systemic setting and organization of the monitoring process of the individual characteristics on a national or a school level. This conclusion is also evident from the opinions of the teachers that they are not satisfied with the basic conditions for this purpose. Namely, there is a lack of specific guidebooks and directions for this process and there is a lack of adequate instruments which would allow objective monitoring and drawing conclusions related to the individual characteristics of the children. The great number of students, as well as the great age difference between the students of a same grade poses another problem.

According to the stated, the teachers cannot provide continuity in the children's portfolios, which should serve as the basis for planning educational activities in a sufficiently objective manner. The insufficient knowledge about the family surrounding of the children additionally burdens the process of getting to know every child separately and renders the entire monitoring process incomplete and non-systemic.

It is encouraging however, that the teachers do know the children they teach. Nevertheless, considering the complexity and subtleness of the support process of the individual development of the children, we believe that the self-organized and enthusiastic approach to this aspect in instruction is not sufficient to create a modern, flexible and individually adapted teaching process. Therefore, in terms of the efforts and movements towards modernized teaching process, it seems that we have yet to achieve a level which would meet the basic postulates of the scientific requirements related to this matter.

Therefore, in the interest of the development and support of the modern school, several key changes related to the matter of our research are required. Namely, the overall analysis of the possibilities for monitoring, recording and support of the individual characteristics of the children stresses the need of change in the organization, program and systemic context of the early school education, in the following directions:

- Establishing a system of standards, criteria, instruments and a guidebook for monitoring and recording the individual characteristics and differences of the children,

- Change of the standards which dictate the number and the age of the children in a same grade, i.e. providing conditions for a lower number of students with a smaller age difference in the same grade, i.e. the first 
grade,

- Establishing criteria and a system for keeping a portfolio for every child, as well as keeping an integral document for comparative recording of the differences among the children within the same grade,

- Providing legally guaranteed conditions, forms and needs to include the family in the educational processes by the teacher and the school, as well as organized detection of the family environment of every student, and - Allowing program flexibility for achieving better accessibility and adaptability of all its aspects to the individual characteristics of the early school-age students.

\section{Conflict of interests}

Author declare no conflict of interest.

\section{REFERENCES}

Bronfenbrener, J., Branković, B., Seizova, T., \& Kol, M. (1997). Ekologija ljudskog razvoja: prirodni i dizajnirani eksperimenti. Zavod za udžbenike $\mathrm{i}$ nastavna sredstva.

Einarsdóttir, J. (2002). Children's accounts of the transition from preschool to elementary school. Tidsskriftet Barn, 4(2002), 49-72. Retrieved from https://www.ntnu.no/documents/10458/19070227/einarsdottir.pdf

Johnston, J., \& Halocha, J. (2010). Early Childhood And Primary Education: Readings And Reflections: Readings \& Reflections. McGraw-Hill International.

Koteva-Mojsovska, T. (2006). Semejnoto vospitanie $i$ socijalnoto odnesuvanje na decata, Skopje: Akademski pecat.

Koteva-Mojsovska, T. (2014). Educational Context and Continuity in the Transition of Children from Preschool toward Primary Education (Proceeding of 9th International Balkan Congress of Education and Science, 16-18 October) Edirne, Trakya University, Turkey. pp. 771-776. Retrieved from http://dosyalar.trakya.edu.tr/egitim/docs/Kongreler/FProceedings.pdf

Peters, S., Hartley, C., Rogers, P., Smith, J., \& Carr, M. (2009). Early childhood portfolios as a tool for enhancing learning during the transition to school. International Journal of Transitions in Childhood, Vol.3,University of Waikato

Samuelsson, I. P., \& Carlsson, M. A. (2008). The playing learning child: Towards a pedagogy of early childhood. Scandinavian Journal of Educational Research, 52(6), 623-641. Retrieved from http:// www.eslov.se/download/18.1bd776c3136a58d 5d74800018338/The+Playing+Learning+Child . pdf 